\title{
Flora do Espírito Santo: Basellaceae
}

\author{
Flora of Espírito Santo: Basellaceae
}

Marco Octávio de Oliveira Pellegrini ${ }^{1,2,4}$ \& Cassia Mônica Sakuragui ${ }^{3}$

\begin{abstract}
Resumo
Basellaceae é uma pequena família de Eudicotiledôneas, composta por quatro gêneros e ca. 20 espécies. No Brasil e no estado do Espírito Santo, é encontrado apenas o gênero Anredera, representado por duas espécies: A. cordifolia e A. tucumanensis. Nós apresentamos descrições, comentários, mapa de distribuição, e ilustrações para todas as espécies.

Palavras-chave: bertalha, Brasil, Caryophyllales, PANC, Portulacineae.
\end{abstract}

\begin{abstract}
Basellaceae is a small family of Eudicots, composed by four genera and ca. 20 species. In Brazil and in the state of Espírito Santo, only Anredera is known to occur, represented by two species: A. cordifolia e $A$. tucumanensis. We present descriptions, comments, distribution map, and illustrations for all species.
\end{abstract}

Key words: madeira-vine, Brazil, Caryophyllales, PANC, Portulacineae.

\section{Introdução}

Basellaceae é uma pequena família de Eudicotiledôneas posicionada em Caryophyllales (APG IV 2016), de distribuição tropical e subtropical, tendo como centro de diversidade a região andina sul americana (Sperling \& Bittrich 1993; Eriksson 2007). Esta família é filogeneticamente próxima à Cactaceae, Didiereaceae, Halophytaceae, Portulacaceae e Talinaceae, tendo em comum o hábito suculento, folhas alternas sem estípulas, ovário unilocular e placentação basal (Nyffeler \& Eggli 2010). Basellaceae compreende quatro gêneros e ca. 20 espécies (Eriksson 2007) dos quais apenas Anredera Juss. é nativo do Brasil, sendo representado por duas espécies (Pellegrini \& Imig 2017). O gênero Basella L. é de origem africana (Sperling 1987; Eriksson 2007) e ocorre no Brasil apenas como subespontâneo ou como cultivado (Pellegrini \& Imig 2017).

\section{Material e Métodos}

A descrição e fenologia das espécies foi baseada em dados de herbários, materiais frescos e em álcool, dados de campo, e quando necessário, complementados com dados de literatura. Todas as espécies foram estudadas em campo por meio de coletas entre os anos de 2010 e 2016. Espécimes das seguintes coleções foram analisados: ALCB, BHCB, BHZB, BM, BOTU, CEPEC, CESJ, CVRD, ESA, FCAB, FLOR, FURB, GUA, HAS, HB, HBR, HRB, HUEFS, HURB, IAC, ICN, MBM, MBML, NY, PMSP, R, RB, RFA, RFFP, SP, SPF, UEC, UPCB e US (acrônimos dos herbários de acordo com Thiers, continuamente atualizado). A classificação da vegetação segue IBGE (2012) e Garbin et al. (2017). A terminologia de formas e indumento segue Radford et al. (1974); a terminologia e morfologia de inflorescências segue Weberling $(1965,1989)$; a terminologia de

\footnotetext{
${ }^{1}$ Universidade de São Paulo, Depto. Botânica, R. do Matão 277, 05508-900, São Paulo, SP, Brasil. marcooctavio.pellegrini@gmail.com

${ }^{2}$ Instituto de Pesquisas Jardim Botânico do Rio de Janeiro, R. Pacheco Leão 915, 22460-030, Jardim Botânico, Rio de Janeiro, RJ, Brasil.

${ }^{3}$ Universidade Federal do Rio de Janeiro, CCS, Inst. Biologia, Depto. Botânica, Av. Carlos Chagas Filho 373, sala A1-088, B1. A, Ilha do Fundão, 21941-902, Rio de Janeiro, RJ, Brasil.

${ }^{4}$ Autor para correspondência: marcooctavio.pellegrini@gmail.com
} 
frutos segue Spjut (1994); e a terminologia geral da família segue Eriksson (2007) e Pellegrini \& Imig (2017). O mapa foi elaborado utilizando o software ArcGis 9.2 (ESRI 2010), shapefiles foram obtidos do IBGE (2014), e coordenadas geográficas foram obtidas de rótulos de materiais herborizados e coletados.

\section{Resultados e Discussão}

No estado do Espírito Santo, Basellaceae está representada pelo gênero Anredera (Pellegrini \& Imig 2017), e as duas espécies listadas para o Brasil. Anredera cordifolia (Ten.) Steenis é considerada uma espécie ruderal, ocorrendo no Espírito Santo na planície litorânea, em floresta ombrófila, restingas, e áreas abertas de Floresta Atlântica. Anredera tucumanensis (Lillo \& Hauman) Sperling é registrada pela primeira vez para o estado do Espírito Santo, sendo conhecida por apenas duas coletas em fragmento de Floresta Estacional Semidecidual Montana da Serra do Mar, no Parque Estadual do Forno Grande.

\section{Basellaceae Raf.}

Trepadeiras volúveis, sem gavinhas, suculentas, herbáceas a levemente lenhosas, ocasionalmente fruticosas. Caule suculento, herbáceo ou lignificado, às vezes produzindo tubérculos aéreos, glabro, raramente pubérulo quando jovem. Folhas simples, alterno-espiraladas, às vezes subopostas na base dos ramos, pecioladas, sem estípulas, glabras, margem inteira, nervura central evidente, nervuras secundárias evidentes ou não. Inflorescências axilares ou terminais, racemos ou panículas, na inserção de cada pedicelo uma bráctea floral, triangular a linear. Flores sésseis ou pediceladas, actinomorfas com exceção do cálice, bissexuais ou raramente funcionalmente unissexuais, casmógamas ou cleistógamas, subtendidas por 2 bractéolas opostas, livres ou conatas; sépalas 2, valvares, opostas, alternadas com as bractéolas, petaloides, persistentes e acrescente nos frutos, livres a parcialmente conatas; pétalas 5, imbricadas, patentes ou eretas, persistentes e levemente acrescentes nos frutos, conatas na base ou até $2 / 3$ do comprimento; estames 5 , livres ou epipétalos, conatos na base ou até 3/4 do comprimento; anteras dorsifixas, bitecas, deiscência rimosa, extrorsa; ovário súpero, gamocarpelar, unilocular, 1-ovulado, placentação basal; estile 1-3, inteiro a trífido até próximo à base; estigma elipsoide ou trilobado a tripartido. Fruto aquênio, envolto apenas na base a completamente envolto pelo perianto persistente. Sementes com a testa membranosa.

Basellaceae apresenta grande importância alimentícia e medicinal, com várias espécies cultivadas para esses fins: bertalha-verdadeira, olluco e folha-gorda (i.e., Basella alba L., Ullucus tuberosus Caldas e Anredera cordifolia, respectivamente).

Anredera Juss., Gen. P1. 84. 1789, nom. cons.

Trepadeiras volúveis, sem gavinhas, suculentas, herbáceas, ocasionalmente sufruticosas. Caule suculento, herbáceo ou lignificado, às vezes produzindo tubérculos aéreos. Folhas simples, alterno-espiraladas, pecioladas; sem estípulas. Inflorescências axilares ou terminais, racemos ou panículas, pedúnculo delgado (não-carnoso), bractéolas conatas ou livres. Flores pediceladas, actinomorfas com exceção do cálice, bissexuais, raramente funcionalmente unissexuais, casmógamas ou cleistógamas, perfumadas, subtendidas por 2 bractéolas; sépalas 2, valvares, opostas, alternas com as bractéolas, petaloides, persistentes e acrescentes nos frutos, livres a parcialmente conatas; pétalas 5 , imbricadas, patentes ou eretas, persistentes e levemente acrescentes nos frutos; estames 5, epipétalos, conatos na base ou até $3 / 4$ do comprimento, estames reflexos no botão floral, anteras dorsifixas, bitecas, rimosas, extrorsas; ovário súpero, gamocarpelar, unilocular, uniovulado, placentação basal, estilete 1-3, inteiro a trífido até próximo à base, estigma capitado ou trilobado. Fruto aquênio, indeiscente, perianto persistente, envolto apenas na base a completamente envolto, membranáceo a paleáceo, castanho a castanho escuro ou negro. Sementes com a testa membranosa.

Anredera é o maior gênero da família, compreendendo ca. 12 espécies (Eriksson 2007). Exclusivamente neotropical, é distribuído desde o sul dos Estados Unidos, passando pelo Caribe, até a Argentina e o Uruguai. Tem como centro de diversidade a região andina da América do Sul. Anredera pode ser facilmente diferenciado de Basella pelas suas inflorescências com raques delgadas (vs. carnosas em Basella), sépalas conatas ( $v s$. livres), flores pediceladas e perfumadas ( $v s$. sésseis e inodoras) e pelo pólen esférico e espinuloso ( $v s$. cuboide e reticulado) (Eriksson 2007; Pellegrini \& Imig 2017). No estado do Espírito Santo está representado pelas duas espécies citadas para o Brasil. 


\section{Chave de identificação das espécies de Basellaceae ocorrentes no Espírito Santo, Brasil}

1. Folhas com margem não revoluta in sicco; pétalas uniformes, patentes; estilete trífido 1. Anredera cordifolia

1'. Folhas com margem levemente revoluta a revoluta in sicco; 2 pétalas mais externas patentes, 3 pétalas mais internas eretas; estilete inteiro 2. Anredera tucumanensis

1. Anredera cordifolia (Ten.) Steenis, Fl. Males., Ser. 1, Spermat. 5(3): 303. $1957 . \quad$ Figs. 1a-e; 2

Trepadeiras suculentas ou ocasionalmente sufruticosas. Caule produzindo tubérculos aéreos quando maduro. Folhas membranáceas a carnosas, verde a verde-escuras, lustrosas; pecíolo $0,2-1,7 \mathrm{~cm}$ compr.; lâminas 1,1-9,5 × 0,7-5 cm, subcordadas a largo-cordadas, raro ovadas ou elípticas, margem não revoluta in sicco. Racemos ou panículas, axilares ou terminais. Flores bissexuais, pedicelos 1-1,5 mm compr.; bractéolas triangulares a largo-ovadas; sépalas 1,5-2,1 × 1,5-2,2 mm, largo-ovadas a largo-elípticas, patentes, alvas a alvo-esverdeadas; pétalas 2,2-3 × 1,3-2,5 mm, uniformes, patentes, elípticas a obovadas, alvas a alvo-esverdeadas; filetes triangulares, alvos, anteras alvas; estilete 1, trífido, estigma capitado. Aquênio envolto apenas na base pelo perianto persistente, patente, castanho.

Material examinado: Guarapari, Praia do Morro, 18.II.1988, fl., L. Krieger 25069 (CESJ). Itaguaçu, Jatiboca, 31.V.1946, fl., A.C. Brade et al. 18501 (NY, RB). Santa Teresa, 25.XI.1953, fl., A.P. Duarte 4008 (HAS, RB).
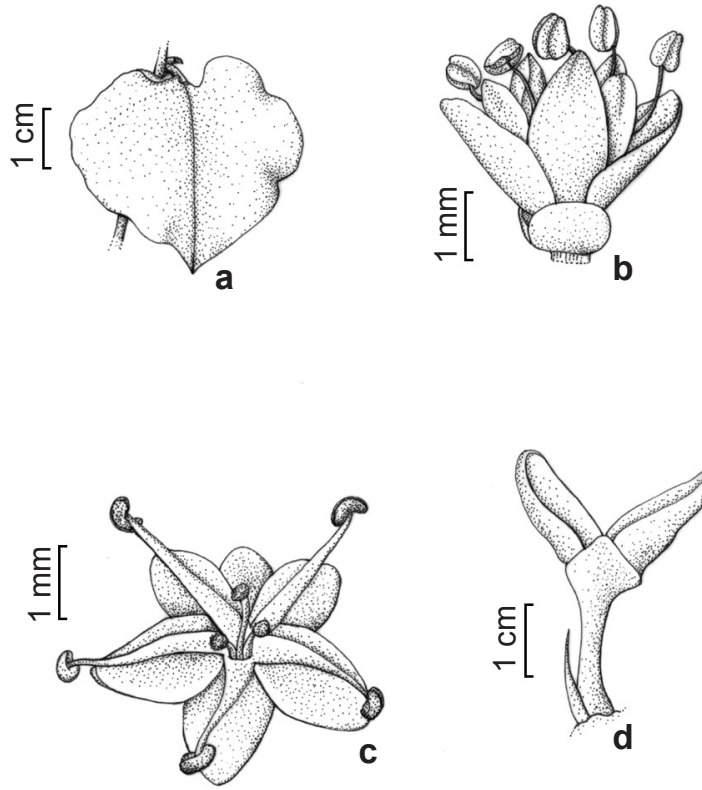

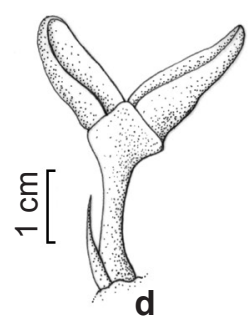

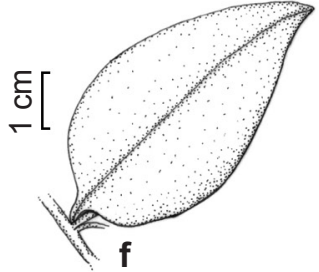
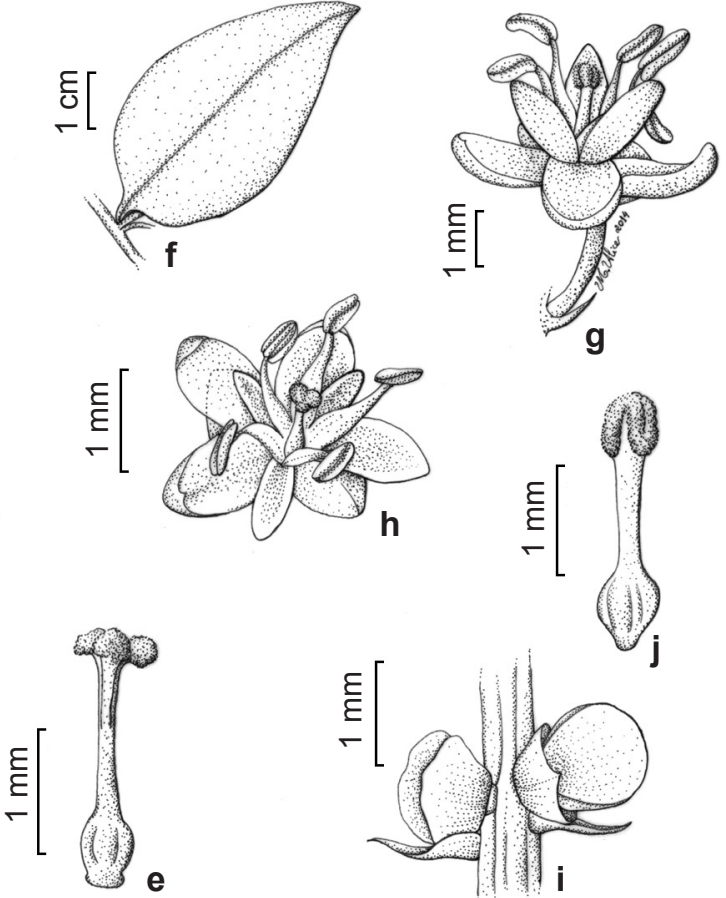
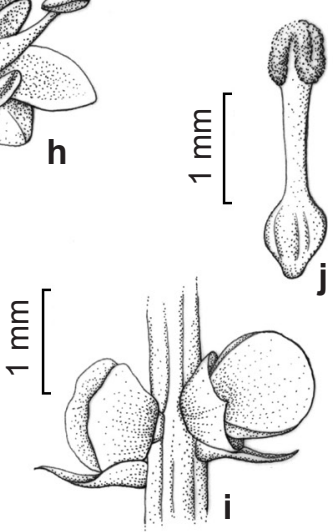

Figura 1 - a-e. Anredera cordifolia - a. folha; b. flor vista de lado; c. flor vista de cima; d. detalhe da bractéola; e. detalhe do gineceu, evidenciando o estilete tripartido. f-j. Anredera tucumanensis - f. folha; g. flor vista de lado; h. flor vista de cima; i. detalhe da bractéola; j. detalhe do gineceu, evidenciando o estilete inteiro. Ilustrações: M.A. Rezende (a-e. M.O.O. Pellegrini 305; f-j. E. Pereira 404).

Figure 1 - a-e. Anredera cordifolia - a. leaf; b. side view of the flower; c. upper view of the flower; d. detail of the bracteole; e. detail of the gynoecium, showing the 3-parted style. f-j. Anredera tucumanensis - f. leaf; g. side view of the flower; h. upper view of the flower; i. detail of the bracteole; j. detail of the gynoecium, showing the entire style. Illustrations: M.A. Rezende (a-e. M.O.O. Pellegrini 305; f-j. E. Pereira 404). 
Material adicional examinado: BRASIL. RIO DE JANEIRO: Cabo Frio, Restinga de Cabo Frio, 21.I.1967, fl., D. Sucre 1436 (HB, RB, UNB). Petrópolis, Castelânea, 16.II.2013, fl., M.O.O. Pellegrini 305 (RB). Rio de Janeiro, estrada para Jacarepaguá, 17.VI.1958, fl. e fr., E. Pereira et al. 3883 (NY, RB, RFA).

Ocorre nas regiões central e sul da América do Sul, sendo registrada no Brasil para os biomas Cerrado, Floresta Atlântica e Pampa (nos estados da Bahia, Ceará, Pernambuco, Mato Grosso do Sul, Espírito Santo, Minas Gerais, Rio de Janeiro, São Paulo, Paraná, Rio Grande do Sul, Santa Catarina) (Eriksson 2007; Pellegrini \& Imig 2017). Anredera cordifolia é considerada uma espécie ruderal bastante comum em antrópicas, especialmente devido à sua vigorosa reprodução clonal por meio da dispersão de seus bulbilhos aéreos. No Espírito Santo, ocorre na planície litorânea, sendo frequente em floresta ombrófila, restingas, e áreas abertas de Floresta Atlântica (Fig. 2). Coletada em flores no Espírito Santo em novembro, fevereiro e maio, frutificando concomitantemente. Devido a dispersão por vento, facilitada pelo perianto persistente e paleáceo, é provável que entre a coleta,

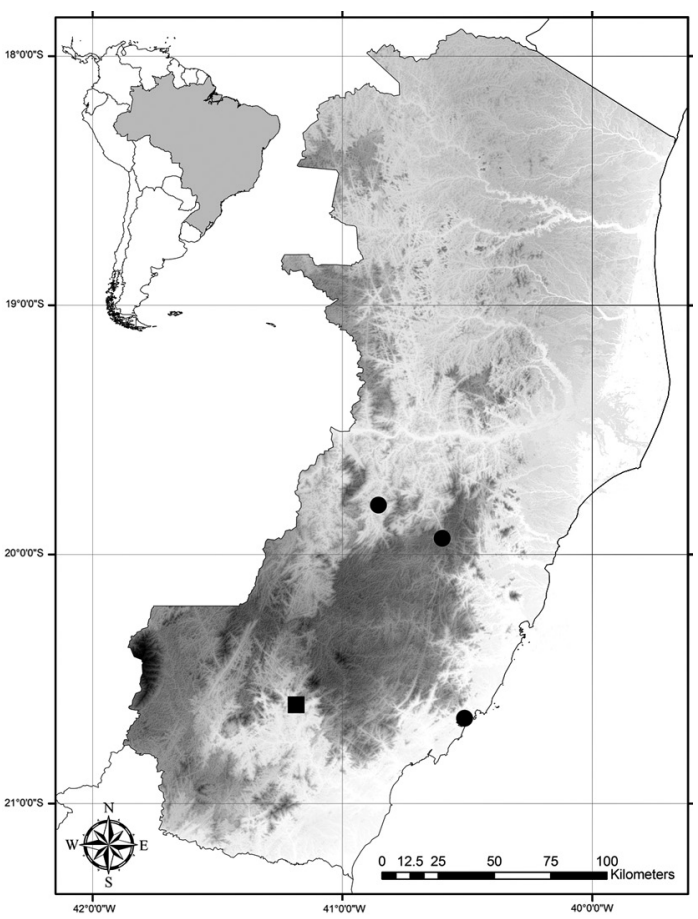

Figura 2 - Mapa de distribuição de Basellaceae no estado do Espírito Santo-(๑) Anredera cordifolia; ( Anredera tucumanensis.

Figure 2 - Distribution map of Basellaceae in the state of Espírito

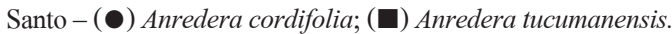

prensagem e secagem dos espécimes, os frutos tenham se desprendido das inflorescências e se perdido. Além disso, devido a intensa reprodução vegetativa de $A$. cordifolia, frutos são formados com menor frequência que em $A$. tucumanensis.

Anredera cordifolia pode ser facilmente diferenciada de $A$. tucumanensis pela presença de bulbilhos aéreos, folhas membranáceas com margem não revoluta in sicco, nervuras secundárias conspícuas, bractéolas conatas, sépalas menores que as pétalas, pétalas uniformes, e estile trífido (Eriksson 2007; Pellegrini \& Imig 2017).

\section{Anredera tucumanensis (Lillo \& Hauman)} Sperling, Phytologia 79(1): 3. 1995. Figs. 1f-j; 2

Trepadeiras suculentas. Caule não produzindo tubérculos aéreos. Folhas carnosas, verde a verdeescuras, lustrosas; pecíolo 3,2-9,4 mm compr.; lâminas $0,8-7,8 \times 0,3-5,6 \mathrm{~cm}$, ovadas a elípticas, margem levemente revoluta a revoluta in sicco. Panículas, raro racemos, axilares ou terminais. Flores bissexuais, pedicelos 0,5-1 mm compr.; bractéolas romboides a rotundas; sépalas 2,5-3× 1,3-1,5 mm, elípticas a obovadas, patentes, alvas a alvo-esverdeadas; pétalas 2,5-3,5 × 1-1,5 mm, elípticas, alvas, 2 pétalas mais externas patentes, 3 mais internas eretas, mais estreitas, mais claras, às vezes menores em comprimento e hialinas; filetes triangulares, alvos, anteras alvas; estilete 1, inteiro, estigma capitado. Aquênio envolto completamente pelas 3 pétalas mais internas, eretas, pétalas externas patentes, perianto castanho.

Material examinado: Castelo, Alto Bananal, orla de mata pluvial, 20.VIII.1987, fl. e fr., G. Hatschbach \& A.C. Cervi 51333 (MBM, UPCB); Parque Estadual do Forno Grande, trilha para a Goela da Onça, 19.VII.2008, fl., $R$. Goldenberg et al. 1193 (CEPEC, MBML, RB, UPCB). Material adicional examinado: BRASIL. MINAS GERAIS: Alto Caparaó, Parque Nacional do Caparaó, ao lado da trilha no Vale Verde, 2.VIII.1996, fl., L.S. Leoni 3405 (ESA). RIO DE JANEIRO: Teresópolis, Serra dos Órgãos, 27.VII.1944, fl. e fr., E. Pereira 404 (HB, RB). Petrópolis, Araras, base da Pedra Maria Comprida, 10.VIII.1968, fl., D. Sucre \& P.I.S. Braga 3455 (CEPEC, INPA, K, MBM, MG, MO, NY, RB).

Nativa do Equador, Bolívia, Argentina e Brasil (nos estados do Espírito Santo, Minas Gerais, Rio de Janeiro, São Paulo, Paraná, Rio Grande do Sul e Santa Catarina) (Eriksson 2007; Pellegrini \& Imig 2017). Apesar da ampla distribuição de $A$. tucumanensis, a espécie é incomum ao longo de sua área de ocorrência, o que é facilmente evidenciado pelo pequeno número de coleções de herbário. Anredera tucumanensis é registrada pela primeira 
vez para o estado do Espírito Santo, onde ocorre em um fragmento de Floresta Estacional Semidecidual Montana da Serra do Mar, no Parque Estadual do Forno Grande (Fig. 2). O registro mais recente de $A$. tucumanensis para o Espírito Santo é representado por indivíduos com inflorescências bastante jovens. Entretanto, a coleta mais antiga (i.e., Hatschbach \& A.C. Cervi 51333; MBM, UPCB) é composta por indivíduos com flores e frutos maduros. Assim, $A$. tucumanensis foi registrada no Espírito Santo com flores entre julho e agosto, e com frutos em agosto.

Anredera tucumanensis pode ser facilmente diferenciada de $A$. cordifolia pela ausência de bulbilhos aéreos, folhas crassas à coriáceas com margem revoluta in sicco, nervuras secundárias inconspícuas, bractéolas livres, sépalas tão longas quanto as pétalas, pétalas dimorfas (as três internas eretas e mais estreitas que as duas externas patentes), e estile inteiro (Eriksson 2007; Pellegrini \& Imig 2017).

\section{Agradecimentos}

A Maria Alice Rezende, a confecção das ilustrações; a Luana Silva Braucks Calazans, Rafael Felipe de Almeida e dois revisores anônimos, as sugestões no manuscrito.

\section{Referências}

APG IV - The Angiosperm Phylogeny Group (2016) An update of the Angiosperm Phylogeny Group classification for the orders and families of flowering plants. Botanical Journal of the Linnean Society 181: $1-20$.

Eriksson R (2007) A synopsis of Basellaceae. Kew Bulletin 62: 297-320.

ESRI - Environmental Systems Research Institute (2010) ARCGIS. Versão 9.3.1. United States of America. Disponível em <https://www.esri.com/en-us/ home $>$. Acesso em 11 março 2017.
IBGE - Instituto Brasileiro de Geografia e Estatística (2012) Manual técnico da vegetação brasileira: sistema fitogeográfico, inventário das formações florestais e campestres, técnicas e manejo de coleções botânicas, procedimentos para mapeamentos. Vol. 1. $2^{\mathrm{a}}$ ed. IBGE, Rio de Janeiro. 272p.

IBGE - Instituto Brasileiro de Geografia e Estatística (2014) Mapa de vegetação do Brasil. Instituto Brasileiro de Geografia e Estatística. Rio de Janeiro, Brasil. Disponível em <http://www.ibge.gov.br/ home/presidencia/noticias/21052004biomashtml. shtm>. Acesso em 29 março 2017.

Nyffeler R \& Eggli U (2010) Disintegrating Portulacaceae: a new familial classification of the suborder Portulacineae (Caryophyllales) based on molecular and morphological data. Taxon 59: 227-240.

Pellegrini MOO \& Imig DC (2017) Basellaceae. In: Flora do Brasil 2020, em construção. Jardim Botânico do Rio de Janeiro. Disponível em <http://floradobrasil. jbrj.gov.br/reflora/floradobrasil/FB57>. Acesso em 13 março 2017.

Radford AE, Dickison WC, Massey JR \& Bell CR (1974) Vascular plant systematics. Harper \& Row, New York. 891p.

Sperling CR (1987) Systematics of the Basellaceae. PhD Dissertation. Harvard University, Cambridge. 291p.

Sperling CR \& Bittrich V (1993) Basellaceae. In: Kubitzki K (ed.) The families and genera of vascular plants. Vol. 4. Springer Verlag, Berlin. Pp. 143-146.

Spjut RW (1994) A systematic treatment of fruit types. The New York Botanical Garden, New York. 181p.

Thiers B [continuamente atualizado] Index Herbariorum: a global directory of public herbaria and associated staff. New York Botanical Garden's Virtual Herbarium. Disponível em $<\mathrm{http}: / /$ sciweb.nybg. org/science2/IndexHerbariorum.asp >. Acesso em 13 março 2017.

Weberling F (1965) Typology of inflorescences. Botanical Journal Linnean Society 59: 15-221.

Weberling F (1989) Morphology of flowers and inflorescences. Cambridge University Press, Cambridge. 348p. 
